\title{
Spawning and Exploitation of Atlantic Herring (Clupea harengus) at Escuminac in the Southwestern Gulf of St. Lawrence, Spring 1983
}

\author{
S. Messieh, R. Pottle', P. MacPherson'1 and T. Hurlbut \\ Department of Fisheries and Oceans, Fisheries Research Branch \\ P. O. Box 5030, Moncton, New Brunswick, Canada E1C 9B6
}

\begin{abstract}
An Atlantic herring (Clupea harengus L.) spawning bed at Escuminac, Miramichi Bay, in the southwestern Gulf of St. Lawrence was surveyed by scuba divers in May 1983. The bed extended 2,200 m along the shore with a mean offshore width of $400 \mathrm{~m}$. Herring were distributed over a depth range of 0.8-3.3 m. The substrate consisted of bedrock and rubble, with Irish moss (Chondrus crispus) and, to a lesser extent, rockweed (Fucus sp.) being the major macrophytes. Bottom temperature ranged from $6.5^{\circ}$ to $9.3^{\circ} \mathrm{C}$ during the incubation period which lasted for 14-16 days. Non-viable herring eggs constituted about $5 \%$ of those examined for stage of development in late May.

Intensity of egg deposition varied from a few scattered eggs to patches which were 4-5 layers deep and was significantly correlated with algal abundance. Mean density of eggs over the entire bed about 10 days after spawning was nearly 25,000 eggs per $\mathrm{m}^{2}$. After adjustment of the estimated deposition of eggs for loss due to predation by fish, use of mean fecundity and mean weight values indicated that the total number of eggs on the spawning bed were produced by approximately 930,400 mature herring (or about 210 tons). The catch of mature herring off Escuminac from the prespawning and spawning concentrations in 1983 was about 4,400 tons. which implies an exploitation rate of $95 \%$. Aerial photographic surveys of fishing activity off Escuminac in 1983 indicated very large concentrations of herring gillnets on and around the spawning ground, and it is believed that these nets caught most of the mature herring before they could spawn.
\end{abstract}

\section{Introduction}

There are two spawning components of herring in the Gulf of St. Lawrence: spring spawners and autumn spawners (Messieh and Tibbo, 1971). The relative importance of the spawning components and the intensity of the spawning beds have changed with time. Historically, the spring-spawning beds around Magdalen Islands and the spring-spawning and autumnspawning beds of Chaleur Bay (Fig. 1A) were the major contributors to herring production in the Gulf (Tibbo et al., 1963). All evidence from biological and biochemical studies of herring in the southern Gulf of St. Lawrence (Parsons and Hodder, 1971; Kornfield et al., 1982 ) indicates that spring and autumn spawners are genetically distinct groups. Circumstantial evidence indicates that the progeny of a spawning component returns to the parental spawning ground (Messieh and Tibbo, 1971).

With the decline of herring stocks in the Gulf of St. Lawrence and the problems associated with stock assessments, the Canadian Atlantic Scientific Advisory Committee (CAFSAC) considered that the present system of managing the herring stocks subjected the different spawning components to unequal exploitation rates and that effective measures to limit the risk of overexploitation of individual components were necessary to conserve the resource (CAFSAC, 1984).
The development of such measures requires that surveys of herring spawning beds and associated fishing activities be undertaken to collect information on egg deposition, spawning biomass and exploitation rates.

One of the major spawning beds in the southern Gulf of St. Lawrence is located at Escuminac (Fig. 1B), and this area has become the center of an intensive spring fishery with the catch amounting to about half the total catch of spring-spawning herring in the southern Gulf. The gillnet fishery is concentrated mainly on the spawning grounds along the shore and the catch consists mainly of adult herring which are concentrating to spawn.

Earlier surveys of herring spawning beds in the Gulf of St. Lawrence have been more qualitative than quantitative in nature (Tibbo et al., 1963). Extensive deposition of eggs at Escuminac occurred in the spring of 1979, when the size of the spawning bed and distribution of eggs were mapped by divers but not quantified (Messieh et al., 1981). That survey indicated that quantitative studies of herring spawning grounds were feasible, and further studies were conducted in 1980 (Pottle et al., 1980) and again in 1981. However, only small spawning beds were found in these years, and the catches of spawning herring were unusually low. Favorable conditions existed in the spring of 1983 which enabled a comprehensive survey of the spawning beds and fishing activity in the Escuminac area to 

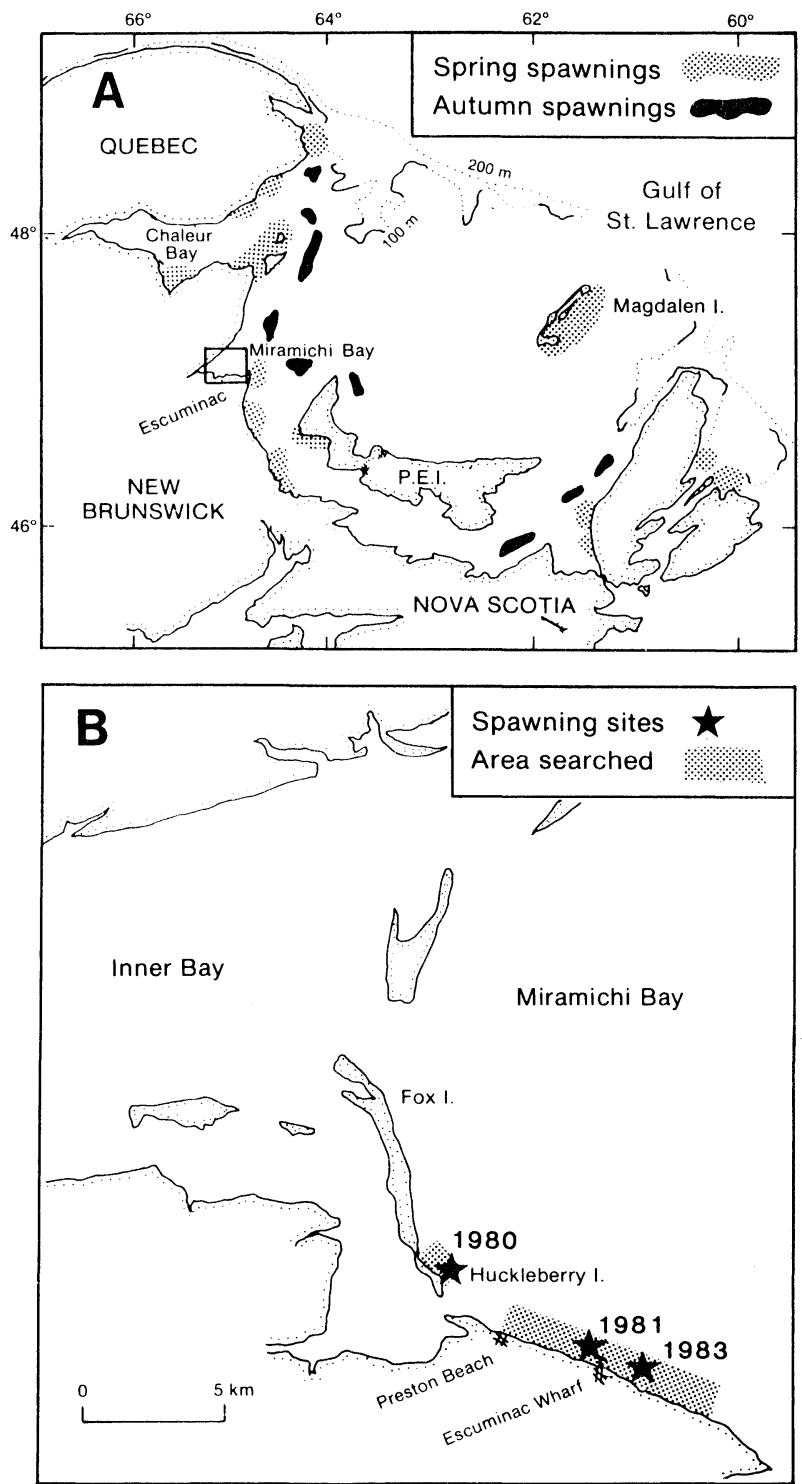

Fig. 1. A, spawning grounds of herring in the southern Gulf of St. Lawrence in the early 1970's (adapted from Messieh, 1976). B. The Escuminac region, Miramichi Bay, where surveys of herring spawning beds were conducted in 1980-83.

be conducted. In this paper the results of the 1983 survey are presented, which involve description and size of the spawning beds, intensity of egg deposition, spawning stock biomass, and exploitation rate.

\section{Materials and Methods}

\section{Searching procedures}

Historical data and previous surveys have shown that the south shore of Miramichi Bay is one of the major spawning grounds of spring-spawning herring in the southern Gulf of St. Lawrence (Fig. 1). The survey in the spring of 1983 was initiated with a search for spawning beds along the shore from Fox Island to Herring Cove, about $5 \mathrm{~km}$ east of Escuminac wharf.
The search grid, with stations about $200 \mathrm{~m}$ apart on transects which were roughly parallel to the shore, extended $1.8 \mathrm{~km}$ offshore and about $10 \mathrm{~km}$ along the shore. The locations of the stations were determined by Loran $\mathrm{C}$ navigation system, with optimum repeatable accuracy (i.e. ability to return to the same position) of $\pm 15 \mathrm{~m}$ (Maloney, 1980). Depths at stations in the search area ranged from 1 to $10 \mathrm{~m}$.

During 27-30 April 1983, divers surveyed the search area for algal cover, the locations of which were plotted on a chart containing the grid of stations. Thereafter, searches for herring spawning beds were concentrated in these areas, because previous studies had shown that substrates with abundant macrophytes are preferred by spawning herring (Pottle et al., 1980; Aneer et al., 1983). The potential spawning area was repeatedly searched from 30 April to 19 May. Fishermen reported schools of herring in shallow water near the shore on 19 May, and a large spawning bed was located east of Escuminac wharf on the morning of 20 May. Divers marked the perimeter of the spawning bed with buoys, the positions of which were determined and plotted on the chart. During 22-26 May, a search of the entire historical spawning area for additional spawning beds yielded negative results.

\section{Quadrate sampling}

A sampling grid was plotted on the map of the spawning bed with stations on transects roughly parallel to the shore and $200 \mathrm{~m}$ apart, except the three transects closest to shore which were $100 \mathrm{~m}$ apart (Fig. 2). The grid consisted of a total of 52 stations of which 35 were within the spawning bed. One of the $200 \times 200$ $\mathrm{m}$ sections (with quadrate sampling stations as corners) was randomly selected for more detailed study. This section was further divided into a grid pattern with 25 sampling stations at $50 \mathrm{~m}$ intervals.

Quadrate sampling began on 26 May. At each station, divers collected all algae and small rocks within a randomly-selected square of $0.25 \mathrm{~m}^{2}$. All loose material and algae scraped from the substrate were propelled into collecting bags by compressed air from the diver's tank. Large rocks and attached herring eggs were placed in separate bags. At the surface, the samples were labelled and preserved in $5 \%$ buffered formalin. The diver recorded sutstrate type, macrophyte cover and intensity of herring egg deposition at each sampling station. The small study area was sampled on 26-27 May and again on 1 June. Stations on the $200 \mathrm{~m}$ grid of the entire spawning bed and those outside the perimeter of the bed were sampled during 28-30 May.

\section{Analysis of quadrate samples}

Each $0.25 \mathrm{~m}^{2}$ sample was partitioned into major macrophyte types, herring eggs, sand, rocks and other debris. Herring eggs were dislodged from algae and 


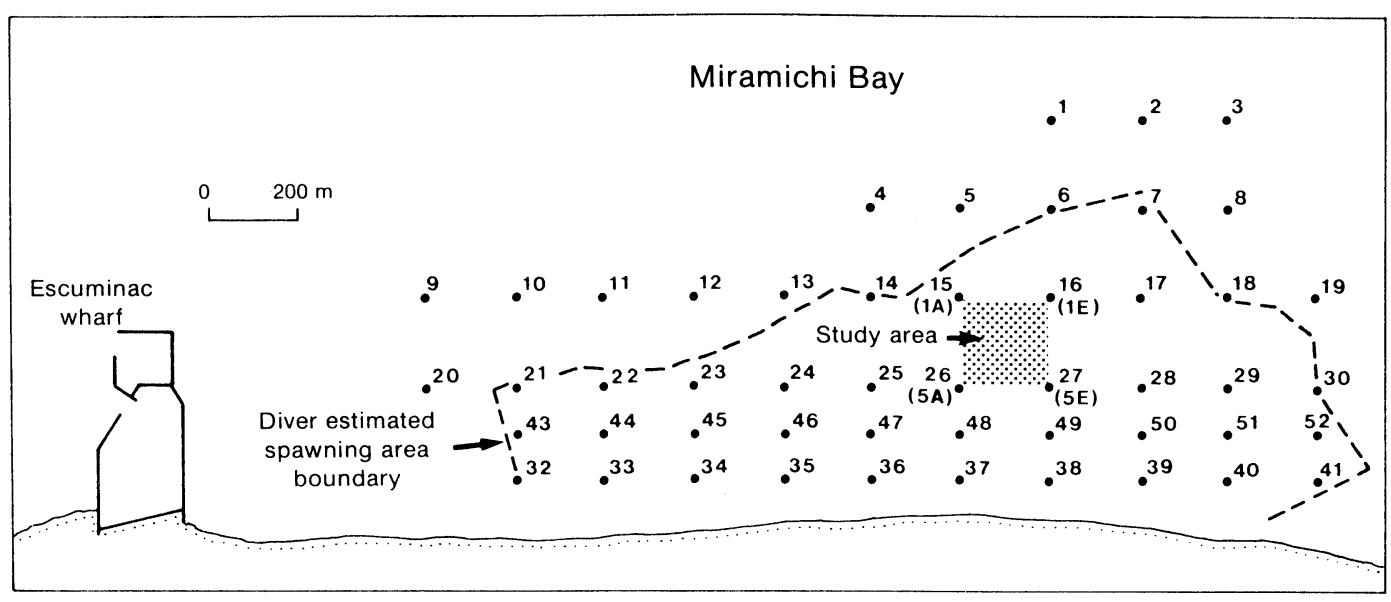

Fig. 2. Herring spawning area near Escuminac, surveyed by scuba divers in May 1983, showing the quadrate sampling stations and boundary of the spawning bed.

rocks with blunt probes. The number of eggs was estimated either by direct count or, in the case of large samples, by volumetric measurement with reference to a calibrated standard number of eggs per millimeter. This standard was the mean number of eggs per unit volume in 32 randomly-selected subsamples. Subsamples of eggs were also selected for determination of developmental stages and viability at the time of collection. Wet weight measurements were determined for the various types of algae which consisted mainly of Chondrus crispus (Irish moss) with some Fucus sp. and Phyllophora sp.

The quadrate data were converted to equivalent values per square meter. The estimated densities of herring eggs were used to estimate the total number of eggs on the spawning bed, and this value was used in conjunction with estimates of mean fecundity and mean weight to determine the approximate size of the spawning population. Variances of the population estimates were calculated by a method described by Goodman (1960). Standard linear regression techniques were used to determine the relationships between egg density $\left(\mathrm{N} / \mathrm{m}^{2}\right)$ and macrophyte abundance $\left(\mathrm{kg} / \mathrm{m}^{2}\right)$ on the basis of the two surveys of the small site and the survey of the entire spawning bed.

\section{Predation on herring eggs}

Demersal fish, primarily winter flounder (Pseudopleuronectes americanus) and various Cottidae, were collected by hand spear throughout May and stomach contents were checked for herring eggs. Collection of fish on the spawning bed for subsequent stomach analysis began on 20 May, when the bed was discovered, and continued throughout the sampling period. During 26 May-1 June, counts were made of all demersal fish within visual range of two 200-m lines which were secured to the bottom along two sides of the small study area. The quantities of herring eggs in the fish stomachs were estimated by volumetric measurement after separation of eggs from other gut contents.

\section{Results}

\section{The spawning bed}

The single herring spawning bed, that was located in the Miramichi Bay area in the spring of 1983, had its western edge about $800 \mathrm{~m}$ west of Escuminac wharf and extended 2,200 $\mathrm{m}$ eastward along the shore (Fig. 2). With a mean offshore width of $400 \mathrm{~m}$ (maximum 650 $\mathrm{m})$, the total area of the bed was estimated to be $880,000 \mathrm{~m}^{2}$. The seaward boundary of the bed corresponded approximately to the offshore limit of macrophyte cover. Herring eggs were densely distributed throughout the bed in depths from 0.8 to $3.3 \mathrm{~m}$ (mean low water).

The substrate consisted of sandstone bedrock and rubble with patches of sand. Irish moss (C. crispus) was the dominant macrophyte in the samples $(82 \%$ of total wet weight of all algae), with Fucus sp. constituting only $16 \%$. Herring egg deposition varied from scattered eggs to patches of eggs which were 1-5 layers deep. Only $53.5 \%$ of the eggs in the samples were attached to macrophytes. Of the remainder, $0.2 \%$ were attached to bare substrate and $46.3 \%$ were loose. It is not known whether the latter were initially unattached or were dislodged during collection and subsequent handling of the samples. Large quantities of herring eggs on rock substrate were recorded at only two stations, both of which were outside the designated perimeter of the spawning bed. The eggs at these stations were believed to be from herring which were trapped in gillnets.

\section{Developmental stages of herring eggs}

Samples of herring eggs for examination of developmental stages were collected prior to and during the period of quadrate sampling (Table 1). The eggs were classified according to the scale of Baxter (1971) as follows:

Stage 1. From fertilization to the formation of the blastula. 
Stage 2. The gastrula stage; head mesoderm not yet differentiated from the trunk mesoderm.

Stage 3. The head region shows some organization; head and trunk are still attached to yolk.

Stage 4. Keel of anterior portion of head rises out clear of yolk; tail has grown out free; eyes may show light pigmentation.

Stage 5. Prehatching stage; embryo is completely formed; eyes heavily pigmented.

Most of the eggs in the samples on 20 May were classified as stage 1. A week after discovery of the spawning bed, $73 \%$ of the eggs were stages 3 and 4 and $21 \%$ were stage 5. Subsequent sampling 3-5 days later revealed that $90-93 \%$ of the eggs were stage 5 . Hatching appeared to be complete by 3 June. Of approximately 3,500 eggs in the three quadrate samples, an average of $4 \%$ were classified as non-fertile. Bottom water temperatures at a station near the spawning bed increased from about $5^{\circ} \mathrm{C}$ on 15 May to $6.5^{\circ} \mathrm{C}$ on 20 May, when the bed was discovered, and to $9.3^{\circ} \mathrm{C}$ in late May when the quadrate sampling was carried out.
TABLE 1. Percent of herring eggs by developmental stage in samples collected before and after quadrate sampling of the Escuminac spawning bed in late May 1983.

\begin{tabular}{ccccccc}
\hline \hline \multirow{2}{*}{ Date } & $\begin{array}{l}\text { No. of } \\
\text { eggs }\end{array}$ & \multicolumn{2}{l}{ Egg developmental stage } & $\begin{array}{c}\text { Not } \\
\text { fertile }\end{array}$ \\
\cline { 3 - 6 }
\end{tabular}

\section{Before quadrate sampling}

$\begin{array}{lrrrrrrr}\text { May 20 } & 397 & 92 & - & - & - & - & 8 \\ \text { May 20 } & 234 & 99 & - & - & - & - & 1 \\ \text { May 21 } & 100 & - & - & - & - & - & 100 \\ \text { May 23 } & 152 & 9 & 1 & 86 & - & - & 4 \\ \text { May 25 } & 176 & - & - & - & 98 & - & 2\end{array}$

After quadrate sampling

\begin{tabular}{lllrrrrr} 
May 26-27 & 1,273 & - & 2 & 35 & 38 & 21 & 3 \\
May 29-30 & 1,139 & - & 1 & 1 & 3 & 90 & 5 \\
Jun 01 & 1,101 & - & - & 1 & 2 & 93 & 4 \\
\hline
\end{tabular}

\section{Egg distribution and macrophyte abundance}

Contoured plots of egg density and macrophyte abundance indicate reasonably good association between these parameters during the first survey of the small study area (Fig. 3, A and B). The association was somewhat less apparent during the second survey of
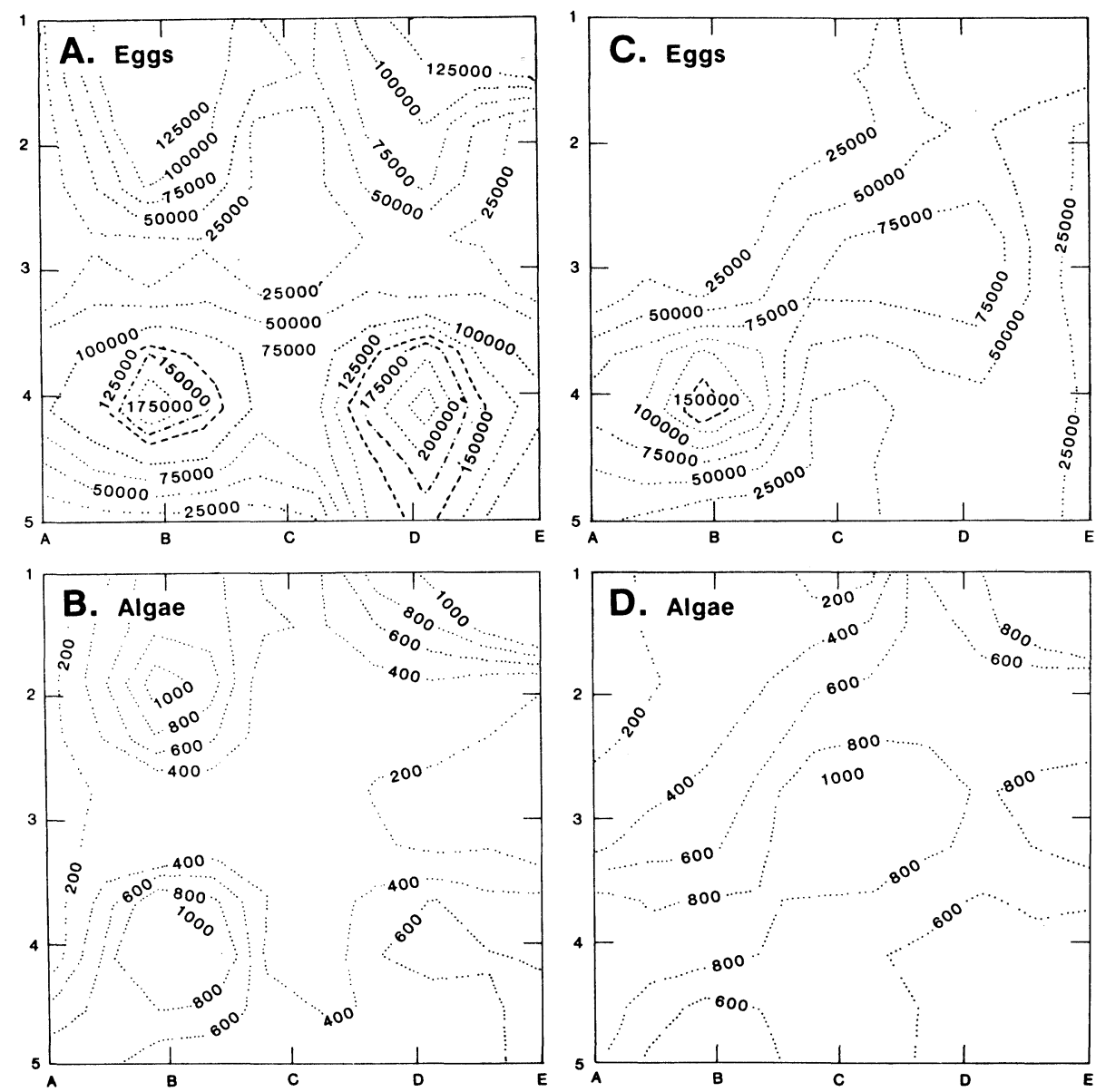

Fig. 3. Contoured plots of herring egg density $\left(\right.$ no. $\left./ \mathrm{m}^{2}\right)$ and algal abundance $\left(\mathrm{g} / \mathrm{m}^{2}\right)$ from the first survey $(\mathbf{A}, \mathbf{B})$ and the second survey $(\mathbf{C}, \mathbf{D})$ of the small study area in the Escuminac spawning bed, 26-27 May and 1 June 1983 
TABLE 2. Average abundance of macrophytes and herring eggs on the Escuminac spawning bed in late May 1983.

\begin{tabular}{|c|c|c|c|c|c|}
\hline \multirow[b]{2}{*}{ Sampled area } & \multirow{2}{*}{$\begin{array}{c}\text { Number } \\
\text { of } \\
\text { stations }\end{array}$} & \multicolumn{2}{|c|}{$\begin{array}{l}\text { Macrophytes } \\
\left(\mathrm{g} / \mathrm{m}^{2}\right) \\
\end{array}$} & \multicolumn{2}{|c|}{$\begin{array}{c}\text { Egg density } \\
\left(\text { no. } / \mathrm{m}^{2}\right)\end{array}$} \\
\hline & & Mean & $\mathrm{SE}$ & Mean & SE \\
\hline Designated spawning bed & 35 & 436 & 82 & 24,666 & 7,448 \\
\hline Outside of bed perimeter & 18 & 198 & 97 & 5,159 & 3,571 \\
\hline Outside of bed perimeter ${ }^{a}$ & 16 & $\ldots$ & $\ldots$ & 13 & 8 \\
\hline Small study area (Ist survey) & 25 & 519 & 113 & 155,398 & 85,644 \\
\hline Small study area (2nd survey) & 25 & 662 & 96 & 43,030 & 9,894 \\
\hline
\end{tabular}

a Omitting data for two stations where spawning herring were trapped in gillnets.

TABLE 3. Regression analysis of herring egg density on algal abundance from surveys of the Escuminac spawning bed in 1983. (* indicates significance at $P<0.01$; all values significant at $\mathrm{P}<0.05$.)

\begin{tabular}{|c|c|c|c|c|c|}
\hline \multirow[b]{2}{*}{ Sampled area } & \multirow[b]{2}{*}{ Regression parameters } & \multirow{2}{*}{$\begin{array}{c}\text { No. of } \\
\text { stations }\end{array}$} & \multicolumn{2}{|c|}{ Regression } & \multirow[b]{2}{*}{$r$} \\
\hline & & & Slope & Intercept & \\
\hline \multirow{2}{*}{ Entire bed } & Total eggs on total algae & 35 & 50.60 & 2,725 & $0.55^{*}$ \\
\hline & Attached eggs on total algae & 35 & 29.83 & 2,774 & $0.51^{*}$ \\
\hline \multirow[t]{3}{*}{ Small area (1) } & Total eggs on total algae & 25 & 374.62 & $-38,745$ & 0.49 \\
\hline & Attached eggs on total algae & 25 & 183.02 & $-20,994$ & $0.56^{*}$ \\
\hline & Attached eggs on Irish moss & 25 & 156.76 & $-3,408$ & $0.58^{*}$ \\
\hline \multirow[t]{3}{*}{ Small area (2) } & Total eggs on total algae & $24^{a}$ & 52.77 & 10,438 & 0.51 \\
\hline & Attached eggs on total algae & $24^{\mathrm{a}}$ & 33.14 & 8,336 & 0.45 \\
\hline & Attached eggs on Irish moss & $24^{\mathrm{a}}$ & 30.49 & 481 & $0.62^{*}$ \\
\hline
\end{tabular}

a Sample from one station was spoiled.

the area 5-6 days later (Fig. 3, C and D), and there was evidently a considerable decrease in abundance of eggs, except perhaps at one station.

Relative to the average weight of macrophytes $\left(\mathrm{g} / \mathrm{m}^{2}\right)$, the average density of herring eggs $\left(\mathrm{N} / \mathrm{m}^{2}\right)$ was. higher in the small study area during both surveys than in the entire spawning bed (Table 2). Some spawning occurred outside the designated boundary of the spawning bed, but nearly all of it was thought to be from herring that were trapped in gillnets at two stations. The omission of data for these stations results in a very low estimate of egg deposition $\left(13 \mathrm{egg} / \mathrm{m}^{2}\right)$ outside the spawning bed. The mean density of eggs in the small study area decreased nearly fourfold between the first and second surveys.

Regression analyses of the data from the survey of the entire spawning bed and from both surveys of the small study area indicated significant $(P<0.05)$ association between the total numbers of eggs (attached and loose) and the weights of algae per square meter, and also between the numbers of attached eggs and the algal weights (Table 3).

\section{Estimated deposition of herring eggs}

The mean density of eggs within the $880,000 \mathrm{~m}^{2}$ spawning bed at Escuminac was slightly less than $25,000 \mathrm{eggs} / \mathrm{m}^{2}$, for an estimated total deposition of 22 $\times 10^{9}$ eggs. The mean density of eggs in the small study area was considerably larger during both surveys than that for the spawning bed as a whole (Table 2), but the mean weight of macrophytes per square meter in this randomly-selected section was greater than that for the entire bed. It is likely, therefore, that the deposition of eggs over the entire bed was closer to the estimate derived from the survey of the entire bed than from the surveys of the small study area.

\section{Predation on herring eggs}

Analysis of stomach contents of various fishes revealed that winter flounder was the major predator. Herring eggs were found in the stomachs of 82 from a total of 90 winter flounder that were collected during the period from 20 May to 3 June. The mean number of eggs per stomach ranged from 2,000 to 5,500 on different days during the sampling period. Data on abundance of winter flounder during 26 May-1 June indicated a mean density of 0.29 fish per $\mathrm{m}^{2}$. On the basis of diurnal feeding periodicity (Frank and Leggett, 1984 ) and feeding frequency of once per day (MacDonald et al., 1982), the estimated daily loss of herring eggs due to predation by winter flounder was at least $2 \%$. Thus, the minimum total loss of eggs during the incubation period, which lasted 14-16 days, was about $30 \%$. Herring eggs were also found in the stomachs of a few sculpins which were collected during 20 May - 3 June, the average being 2,260 eggs per stomach in 17 of 36 specimens. However, the mean density of sculpins was very low $\left(<0.02 / \mathrm{m}^{2}\right)$, and the egg loss was estimated to have been less than $0.2 \%$ during the incubation period. 


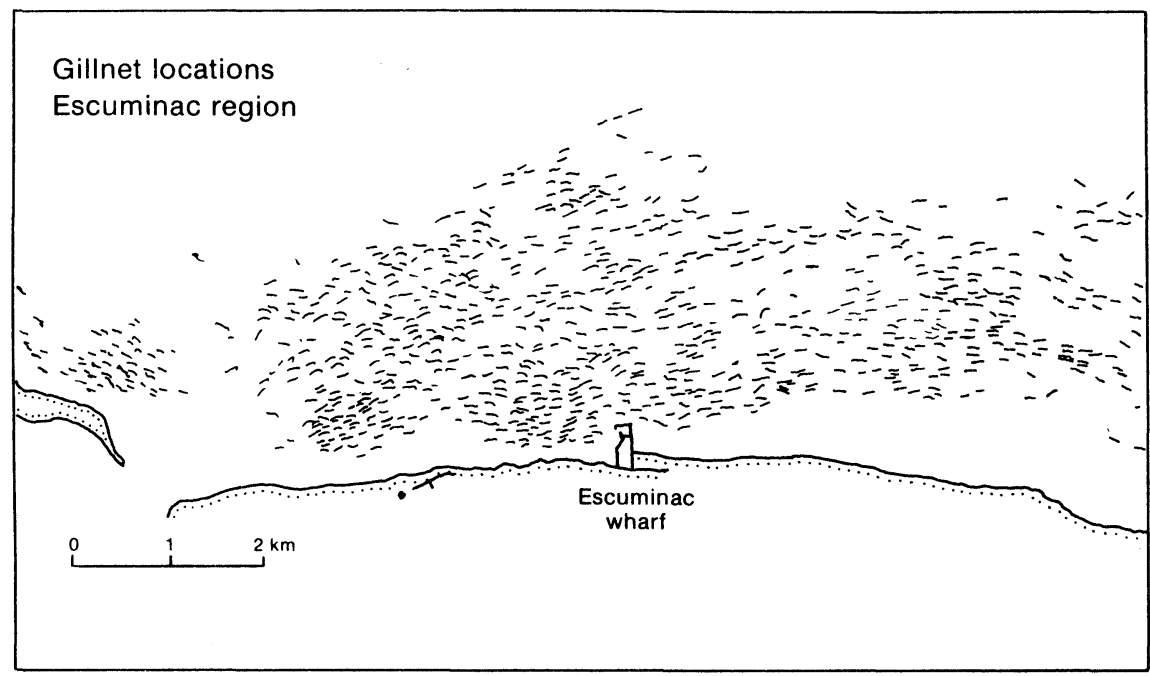

Fig. 4. Distribution of herring gillnets in the Escuminac area during the spawning season in May 1983, as determined from aerial photographic surveys.

\section{Composition of the catch}

The gillnet fishery at Escuminac in 1983 was concentrated mainly along $8 \mathrm{~km}$ of shoreline, and aerial photographic surveys showed an average of 770 standard gillnets per day during the prespawning and spawning period from 28 April to 1 June (Fig. 4). Total length of deployed nets averaged $21.1 \mathrm{~km}$ per day. In 1983 , the total recorded catch of herring in the area was about 4,000 (metric) tons, and additional amounts totalling approximately 800 tons were dumped at sea because of limited processing facilities. The concentration of the fishery on the capture of maturing and ripe herring before spawning began was clearly demonstrated from sampling, whereby $78.3 \%$ of herring in the catch were maturity stages 4 and 5 (maturing), $7.4 \%$ were stage 6 (ripe) and only $4.1 \%$ were stage 7 (spent). The remaining $10 \%$ of the catch consisted mainly of immature fish. Thus, the total catch of mature herring was probably about 4,400 tons.

\section{Spawning biomass and exploitation rate}

Data from biological sampling of the herring fishery at Escuminac in 1983 were used to estimate the spawning biomass and exploitation rate (Table 4). The large catch of mature herring before and during the spawning period relative to the estimated spawning biomass implied that the exploitation rate was about $95 \%$.

The biological parameters that were used in the calculations, particularly the mean length, weight and fecundity values, are higher than those obtained in previous studies of the spring-spawning herring population in the southern Gulf of St. Lawrence (e.g. Hodder, 1972; Hodder et al., 1972; Messieh, 1976). These earlier studies were conducted when herring
TABLE 4. Age composition of the herring catch and biological data relevant to calculation of spawning biomass and exploitation rate in the Escuminac area in 1983.

\begin{tabular}{|c|c|c|c|c|}
\hline $\begin{array}{l}\text { Age } \\
\text { (yr) }\end{array}$ & $\begin{array}{c}\text { Catch } \\
\text { composition } \\
(\%)\end{array}$ & $\begin{array}{l}\text { Mean } \\
\text { length } \\
(\mathrm{cm})\end{array}$ & $\begin{array}{l}\text { Mean } \\
\text { weight } \\
\text { (g) }\end{array}$ & $\begin{array}{c}\text { Mean } \\
\text { fecundity } \\
(000)\end{array}$ \\
\hline 3 & 20.1 & 27.9 & 185 & 59 \\
\hline 4 & 65.5 & 29.8 & 231 & 67 \\
\hline 5 & 10.9 & 31.5 & 249 & 79 \\
\hline 6 & 3.2 & 32.2 & 265 & 90 \\
\hline \multirow[t]{2}{*}{7} & 0.3 & 33.0 & 322 & 104 \\
\hline & Weighted mean & 29.7 & 225 & 67.5 \\
\hline \multicolumn{4}{|c|}{ Estimated total egg deposition $\ldots \ldots \ldots \ldots \ldots$} & $22.0 \times 10^{9} \quad(\mathrm{~A})$ \\
\hline \multicolumn{4}{|c|}{ Proportion lost by fish predation $\ldots \ldots \ldots \ldots \ldots$} & $0.30 \quad(B)$ \\
\hline \multicolumn{4}{|c|}{ Initial egg deposition, $\mathrm{A} /(1-\mathrm{B})$. } & $31.4 \times 10^{9} \quad(\mathrm{C})$ \\
\hline \multicolumn{4}{|c|}{ Weighted average fecundity ....... } & 67,500 (D) \\
\hline \multicolumn{4}{|c|}{ Number of spawning females, C/D } & 465,200 (E) \\
\hline \multicolumn{4}{|c|}{ Total males and females, $2 \mathrm{E}$} & $930,400(F)$ \\
\hline \multicolumn{4}{|c|}{ Mean weight of herring $\quad \ldots \ldots \ldots \ldots \ldots \ldots$} & $0.225 \mathrm{~kg}(\mathrm{G})$ \\
\hline \multicolumn{4}{|c|}{ Estimated spawning biomass, $\mathrm{F} \times \mathrm{G} / 1000$} & 209.3 tons $(H)$ \\
\hline \multicolumn{4}{|c|}{ Catch of spawning fish $\ldots \ldots \ldots \ldots$} & 4,400 tons $(1)$ \\
\hline \multicolumn{4}{|c|}{ Exploitation rate, $100 \times \mathrm{l} /(\mathrm{H}+\mathrm{l})$} & $95.4 \%$ \\
\hline
\end{tabular}

were much more abundant than at present. A recent study by Messieh et al. (MS 1985) indicates that the biological parameters have changed significantly in association with the sharp decline in size of the herring population in recent years.

\section{Discussion}

Although the herring spawning bed at Escuminac in 1983 was much larger than that at Huckleberry Island, Miramichi Bay (Pottle et al., 1980), the physical characteristics were similar. The substrate at both sites consisted of rubble and bedrock, and Irish moss ( $C$. crispus) was the dominant macrophyte. The maximum depth of the Escuminac bed was less than that 
recorded at the other site, due probably to the absence of significant algal cover on the sandy substrate outside the designated boundary of the Escuminac bed.

Previous surveys of herring spawning beds on both the Atlantic and Pacific coasts of Canada have shown direct relationships between the intensity of egg deposition and the degree of algal cover (Tibbo et al., 1963; Haegele et al., 1979; Pottle et al., 1980). In the present study, despite the variability in the data from the two surveys of the small study area and that of the entire bed, egg density was significantly correlated with algal abundance. Spawning was insignificant in depths greater than $3.3 \mathrm{~m}$ outside the boundary of the Escuminac bed, where algal cover was much less extensive, but spring spawning beds with an abundance of macrophytes have been found to extend to greater depths (e.g. Pottle et al., 1980).

There was a large reduction (72\%) in the mean density of eggs in the small study area between the surveys on 26-27 May and 1 June. This decrease can be attributed in part to hatching, because egg development was evidently rapid during that period (Table 1), but predation by demersal fish was a contributing factor. In addition, the shallowness of the spawning bed (1-3 m) made it particularly vulnerable to disruption by wave action, whereby eggs are detached from macrophytes and macrophytes are dislodged from the substrate and washed ashore by strong winds. Such action may result in considerable egg mortality (Tibbo et al., 1963). However, examination of algae washed ashore along the beach at Escuminac revealed very few eggs and macrophytes with attached eggs.

The discovery of the Escuminac spawning bed while the eggs were at developmental stage 1 (i.e. approximately $24 \mathrm{hr}$ after fertilization), enabled determination of the actual duration of the incubation period in nature. In 1983, this period lasted 14-16 days, in comparison with estimates of about 15 days from the survey at Huckleberry Island in 1980 (Pottle et al., 1980) and about 17 days from the survey of a small spawning bed near Escuminac in 1981 (R. Pottle, unpubl. data). There was no spawning bed at Escuminac in 1982. The intensity of egg deposition in 1983 was greater than that on the small beds which were surveyed in 1980 and 1981 but considerably less than that which was reported by Tibbo et al. (1963) for a spring-spawning bed north of Escuminac in Chaleur Bay.

Spawning activity was evidently more widespread throughout the historical spawning area in 1979 than in subsequent years, although quantitative data are lacking (see Messieh et al., 1981, fig. 6 and 7). However, there was a considerable increase in the herring catch at Escuminac in 1983 relative to those of the 3 preceding years, and that catch (4,800 tons) represented approximately half of the overall catch of springspawning herring in the southern Gulf of St. Lawrence. Fishing activity was apparently very intense, as indicated by the extremely high exploitation rate which was estimated to have exceeded $90 \%$ on the basis of egg deposition in relation to catch and spawning potential.

Several factors could influence the estimates of the exploitation rates. One possibility is that there were additional spawning beds which were not located during the survey of the region, but this is highly unlikely because repeated and systematic searches of the historical spawning areas by scuba divers did not reveal any other beds and fishermen did not report any concentrations of spawning herring other than that which produced the spawning bed east of Escuminac wharf. The second possibility is that egg loss during the incubation period had exceeded considerably the estimate of $30 \%$ due to predation by fish. However, even if total egg mortality was assumed to be as high as $50 \%$, the exploitation rate would still exceed $90 \%$ because of the high catch of herring in the vicinity of the spawning bed. The third possibility is that a significant portion of the Escuminac concentration left the area in late May to spawn at alternative sites. This was very unlikely, because information on spawning locations and spawning times, gathered from aerial photographic surveys of gillnet distribution and an extensive herring sampling program, did not substantiate the mass movement of herring away from the Escuminac area.

Alternatively, the high exploitation rate may have resulted from failure of the majority of the herring to reach the traditional spawning bed near shore due to capture. This possibility is substantiated by the aerial photographic surveys in 1983 which showed a great concentration of herring gillnets (mesh sizes of 5.3-5.8 $\mathrm{cm}$ ) on and around the spawning bed (Fig. 4). This concentration of small-meshed gillnets posed a formidable barrier to migrating herring.

The results of this survey indicate that spawning bed surveys are potentially useful for herring stock assessment. At present, the method is limited to the Gulf of St. Lawrence spring-spawning population which spawns in shallow depths $(<10 \mathrm{~m})$. Scuba surveys of the deeper autumn-spawning sites are also feasible but they would require more manpower due to restrictions on underwater working time in order to avoid decompression. Even so, autumn surveys by divers would be more cost effective than those by submersibles (e.g. Caddy and Iles, 1973). Although the concept of herring stock assessment by surveying spawning beds is new to fisheries of the Atlantic coast of Canada, a similar method has been used successfully for many years on the Pacific coast (Humphreys and Hourston, 1978; Hourston and Schweigert, 1981). 
The status of the British Columbia herring stocks is assessed annually on the basis of routine monitoring of the catch and egg deposition. The latter is converted to number of fish at age in the escapement from age compositions of catches, sex ratios and fecundity-atage data (Stocker et al., 1983).

Data from spawning bed surveys are particularly useful in providing estimates of stock biomass which are independent of those based on sequential population analyses. The accuracy of herring biomass estimates from sequential population analyses was recently questioned by Sinclair et al. (1985), who showed that, for three major herring populations in the Northwest Atlantic (including herring in the southern Gulf of St. Lawrence), the stock assessments have tended to seriously underestimate the declines in abundance and overestimate the mild upswings. They concluded that Atlantic herring should be managed conceptually as the salmon stocks are, by monitoring fish escapement (from estimates of egg deposition) and subsequently controlling fishing activity on the spawning ground. However, for the herring population which spawns at Escuminac, it is not practical to use egg deposition as a measure of "escapement" to control fishing effort, because there is little or no time lag between fishing time and herring spawning. Most of the catch is taken in a period of 3 weeks, which coincides with the period of peak spawning. Escapement of herring for spawning could be significantly enhanced if fishing effort was controlled by alternating periods of fishing and non-fishing days.

\section{Acknowledgement}

The herring spawning bed survey was carried out by Murdoch, Pottle and Macpherson Marine Services, Halifax, Nova Scotia, under a contract with the Canadian Department of Supply and Services. The diving tender Mysis was on loan from the Biological Station, St. Andrews, New Brunswick. The diving operations were conducted by C. Bourque, B. Gill and J. Stairs. Our thanks go to T. D. lles for reviewing an earlier draft of this paper.

\section{References}

ANEER, G., G. FLORELL, U. KAUTSKY, S. NELLBRING, and L. SJOSTEDT. 1983. In situ observations of Baltic herring (Clupea harengus membros) spawning behaviour in the Asko-Landsort area, northern Baltic proper. Mar. Biol., 74: $105-110$.

BAXTER, I. G. 1971. Development rates and mortalities in Clyde herring eggs. ICES Rapp. Proc.-Verb., 160: 27-29.

CADDY, J. F., and T. D. ILES. 1973. Underwater observations on herring spawning grounds on Georges Bank. ICNAF Res. Bull., 10: 132-239.

CAFSAC. 1984. Management of the herring fishery in the southern Gulf of St. Lawrence. CAFSAC Ann. Rep. for 1983, 6: 139-141.

FRANK, K., and W. C. LEGGETT. 1984. Selective exploitation of capelin (Mallotus villosus) eggs by winter flounder (Pseudopleuronectes americanus): capelin egg mortality rates, and contribution of egg energy to the annual growth of flounder. Can. J. Fish. Aquat. Sci., 41: 12941302.

GOODMAN, L. A. 1960. On the exact variance of products. J. Amer. Stat. Assoc., 55: 708-713.

HAEGELE, C. W., A. S. HOURSTON, R. D. HUMPHREYS, and D. C. MILLER. 1979. Eggs per unit area in British Columbia herring spawn depositions. Can. Fish. Mar. Serv. Tech. Rep., 894: 30 p.

HODDER, V. M. 1972. The fecundity of herring in some parts of the Newfoundland area. ICNAF Res. Bull., 9: 99-107.

HODDER, V. M., L. S. PARSONS, C. I. BARBOUR, and R. CHAULK. 1972. Length, age and weight of herring in the southwest Newfoundland winter fishery from 1965-66 to 1970-71. Fish. Res. Board Can. Tech. Rep., 339: 113 p.

HOURSTON, A. S., and J. F. SCHWEIGERT. 1981. Procedures for assessing and forecasting British Columbia herring stocks from catch, sampling and spawn deposition data. Can. Tech. Rep. Fish. Aquat. Sci., 1000: 58 p.

HUMPHREYS, R. D., and A. S. HOURSTON. 1978. British Columbia herring spawn deposition manual. Can. Fish. Mar. Serv. Spec. Publ., 38, 40 p.

KORNFIELD, I., B. D. SIDELL, and P. S. GAGNON. 1982. Stock definition in Atlantic herring (Clupea harengus harengus): genetic evidence for discrete fall and spring spawning populations. Can. J. Fish. Aquat. Sci., 39: 16101621.

MacDONALD, J. S., K. G. WAIWOOD, and R. H. GREEN. 1982. Rates of digestion of different prey in Atlantic cod (Gadus morhua), ocean pout (Macrozoarces americanus), winter flounder (Pseudopleuronectes americanus), and American plaice (Hippoglossoides platessoides). Can. J. Fish. Aquat. Sci., 39: 651-659.

MALONEY, E. S. 1980. Chapman piloting seamanship and small boat handling. Hearst Books (54th ed.), New York, N.Y., 521 p.

MESSIEH, S. N. 1976. Fecundity studies on Atlantic herring from the southern Gulf of St. Lawrence and along the Nova Scotia coast. Trans. Amer. Fish. Soc., 105(3): 384394.

MESSIEH, S. N., and S. N. TIBBO. 1971. Discreteness of Atlantic herring (Clupea harengus L.) population in spring and autumn fisheries in the southern Gulf of St. Lawrence. J. Fish. Res. Board Can., 28: 1009-1014.

MESSIEH, S. N., D. J. WILDISH, and R. H. PETERSON. 1981. Possible impact from dredging and soil disposal on the Miramichi Bay herring fishery. Can. Tech. Rep. Fish. Aquat. Sci., 1008: $33 \mathrm{p}$.

MESSIEH, S., V. ANTHONY, and M. SINCLAIR. MS 1985. Fecundities of Atlantic herring (Clupea harengus L.) populations in the Northwest Atlantic. ICES C. M. Doc., No. $H: 8,26 \mathrm{p}$.

PARSONS, L. S., and V. M. HODDER. 1971. Meristic differences between spring- and autumn-spawning Atlantic herring (Clupea harengus) from southwestern Newfoundland. J. Fish. Res. Board Can., 28: 553-558.

POTTLE, R. A., P. A. MacPHERSON, S. N. MESSIEH, and D. MOORE. 1980. A scuba survey of a herring (Clupea harengus L.) spawning bed in Miramichi Bay, N. B. Can. Tech. Rep. Fish. Aquat. Sci., 984: 14 p. 
SINCLAIR, M., V. C. ANTHONY, T. D. ILES, and R. N. O'BOYLE. 1985. Stock assessment problems in Atlantic herring (Clupea harengus) in the Northwest Atlantic. Can. J. Fish. Aquat. Sci., 42: 888-898.

STOCKER, M., V. HAIST, and D. FOURNIER. 1983. Stock assessment of British Columbia herring in 1982 and fore- casts of the potential catch in 1983. Can. Tech. Rep. Fish. Aquat. Sci., 1158: 53 p.

TIBBO, S. N., D. J. SCARRATT, and P. G. MCMULLON. 1963. An investigation of herring (Clupea harengus L.) spawning using free diving techniques. J. Fish. Res. Board Can., 20: $1067-1079$. 
